\title{
Carybdea alata auct. (Cubozoa): rediscovery of the Alatina grandis type
}

\author{
BASTIAN BENTLAGE ${ }^{1,2}$ \\ ${ }^{1}$ Department of Ecology and Evolutionary Biology, The University of Kansas, 1200 Sunnyside Avenue, Lawrence, KS 66045, USA. \\ E-mail: bentlage@ku.edu \\ ${ }^{2}$ NMFS, National Systematics Laboratory, National Museum of Natural History, MRC-153, Smithsonian Institution, PO Box 37012 , \\ Washington, DC 20013-7012, USA
}

Numerous nominal species have been considered synonymous with Carybdea alata Reynaud, 1830 (cf. Gershwin 2005). A recent revision concluded that several of the species collectively referred to as $C$. alata are valid and indeed separate species (Gershwin 2005; but see also Bentlage et al. 2010). Additionally, these species (including C. alata) were moved into the genus Alatina Gershwin 2005 (family Alatinidae Gershwin, 2005) because of stark morphological differences they display compared to the other species of Carybdea. In particular, Alatina species possess crescentic phacellae and a rhopaliar niche ostium that is covered by a single upper and two lateral scales (t-shaped sensu Gershwin 2005; cf. Bigelow 1938) compared to a single upper covering scale (heart-shaped sensu Gershwin 2005; cf. Bigelow 1938) and epaulette-like or linear phacellae in the corners of the stomach in Carybdea species. Recent molecular phylogenetic analyses support the separation of Carybdea and Alatina (Bentlage et al. 2010). Alatina grandis posed a problem in Gershwin's (2005) revision, as the type of this species appeared to be lost to science, preventing a closer investigation of its identity. I located a type specimen of the species in the collections of the National Museum of Natural History, Smithsonian Institution (USNM). The purpose of this letter is to draw attention to this important specimen, and highlight directions for future studies on the evolutionary history of the genus Alatina.

Alatina grandis (Agassiz \& Mayer, 1902). Agassiz \& Mayer (1902) described A. grandis, the largest known nominal species of Alatina, from material collected by the steamer Albatross off Fakarava and Anaa Island in the Tuamotu Archipelago (Paumotu Islands at the time; see also Mayer 1910). Even though the authors included much detail in their description, a reinvestigation of this species seems necessary in light of recent taxonomic work. Agassiz \& Mayer (1902) clearly investigated multiple specimens and observed a large variation in size among individuals, the largest one having a bell height of $230 \mathrm{~mm}$. A single large specimen, USNM 42114, agrees well with the description given by Agassiz \& Mayer (1902) and the labels contained in the jar clearly show that it was collected at the water surface off Anaa Island on board the steamer Albatross on October 15, 1899, matching the collection data in the original description of the species. Additionally, the original labels appear to bear A.G. Mayer's handwriting.

Fig. 1A shows the habitus of the specimen, a large individual of more than $200 \mathrm{~mm}$ bell height. The gelatinous substance of the bell seems rather thick compared to other species of Alatina. The bell is broken in the upper quarter and the specimen is generally in poor condition. Exumbrella and pedalia appear void of nematocyst warts. The pedalia are large and possess a prominent keel (Fig. 1B; cf. Plate 6 in Agassiz \& Mayer 1902). The rhopaliar niche ostium is covered by one upper and two lateral covering scales like the rhopaliar niche ostia of all other members of the family Alatinidae (Fig. 1C). The rhopalia are either missing (cf. Fig. 1C) or quite deteriorated. I did not investigate the rhopalia closer in order to count the number of eyes present, so as not to damage the fragile specimen further. Agassiz \& Mayer (1902) report a varying eye number, but they are not explicit as to whether they observed the eyes in live specimens or after these had been fixed for some period of time. In the latter case the pigment of the eyes may have faded and the lenses deteriorated leading to inaccurate counts. The velarium is nearly completely missing in USNM 42114 and the number and shape of velarial canals cannot be determined. Agassiz \& Mayer (1902) report three velarial canals per octant and well-developed frenulae. The phacellae, described as crescentic and lining the stomach in the interradii, are only preserved in one stomach corner in USNM 42114. Individual gastric cirri seem to arise from a single trunk that then branches in a tree-like fashion (Fig. 1D).

Nematocysts were not reported from A. grandis before. I investigated both the cnidome of the tentacles and gastric cirri. The following measurements are given as Min-Mean-Max in $\mu \mathrm{m}$ and identifications follow Mariscal (1974); heteronemes displaying a v-shaped notch in the undischarged shaft were classified as "p-" following Östman (2000). The tentacles contained small spherical isorhizas (length: 13.3-14-14.6, width: 12.7-13.5-14, n=5; Fig. 1E), small oval pheteronemes (length: 12.7-14.3-15.7, width: 11.1-11.9-12.9, n=15; Fig. 1F-G), and large cigar-shaped p-heteronemes 
(length: 39-40.4-41.7, width: 12.9-15.2-17.4, n=8; Fig. 1H-J). Gastric cirri contained the same large p-heteronemes as the tentacles (length: 40.7-43.6-45.1, width: 14.6-15.8-17.1, $\mathrm{n}=8$ ). A small oval capsule (length: 15.6-16.3-16.9, width: 10.8-12.6-13.9, $\mathrm{n}=2$ ) was also contained in the cirri, but the internal structure of all capsules observed was highly damaged. Given the shape and size it is likely identical to the small p-heteroneme found in the tentacles. The observed nematocysts were generally undischarged, but several of the large capsules were discharged. However, all discharged nematocysts lacked shaft and tubule, making more detailed identification of nematocysts impossible.

Remarks. With conflicting views over the validity of some Alatina species (compare Gershwin 2005 with Bentlage et al. 2010 concerning A. moseri and A. mordens), the specimen described above may prove valuable in future studies. Currently, Gershwin (2005) considers many regionally restricted species of Alatina valid, whereas Bentlage et al. (2010) suggest that several of these nominal species of Alatina may actually represent single widespread species. In particular, Bentlage et al. (2010) showed that A. mordens Gershwin, 2005 from the Coral Sea and A. moseri (Mayer, 1906) from Hawai'i likely represent the same species based on molecular genetic data (the mitochondrial 16S gene). In this context, A. grandis is of great interest. Alatina grandis was discovered somewhat in between these two geographic locations and may also be part of this potentially widespread species (cf. Mayer 1910 who considered A. moseri a small variety of $A$. grandis). Future work on Alatina should involve reevaluating the variability of morphological characters currently employed for species delineation in light of additional molecular data to decide upon the nature of the nominal Alatina species.

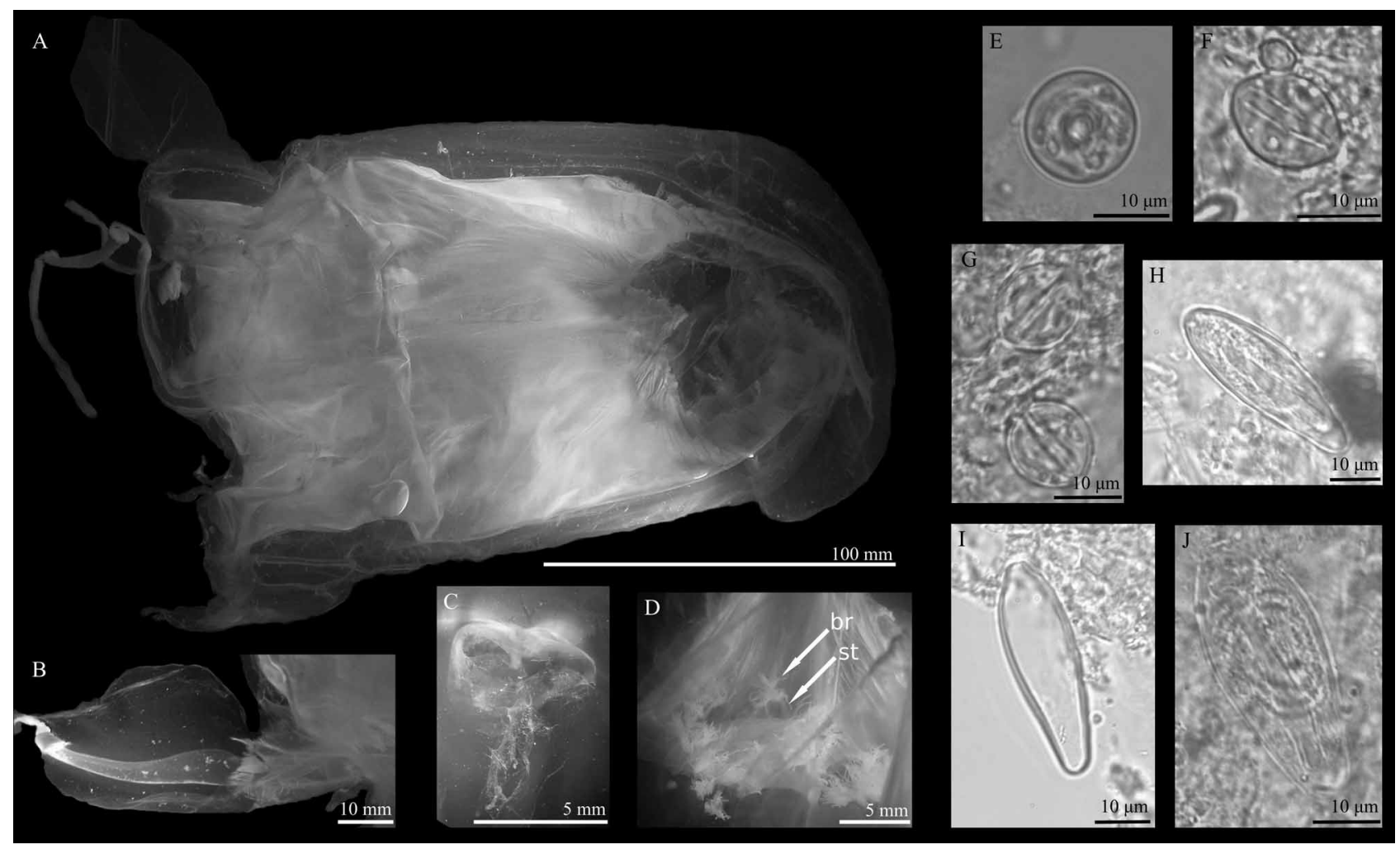

FIGURE 1. A: habitus of the specimen (note the break in the upper portion of the bell); B: pedalium; C: rhopaliar niche with a single upper and two lateral covering scales (the rhopalium is missing and only the stalk remains); D: gastric phacellus with individual cirri in the stomach cavity (br: branching part of cirrus, st: stalk of cirrus); E: spherical isorhiza; F \& G: small oval p-heteroneme; H-J: large cigar-shaped p-heteroneme (H \& J undischarged; I: discharged).

\section{Acknowledgements}

I wish to acknowledge the Smithsonian Institution for awarding a pre-doctoral fellowship to me. Additionally, my research is funded through US NSF Assembling the Tree of Life grant EF-053179 to Paulyn Cartwright, Allen G. Collins, and Daphne Fautin, and US NSF Doctoral Dissertation grant DEB-0910237. 


\section{References}

Agassiz, A. \& Mayer, A.G. (1902) Reports on the scientific results of the expedition to the tropical Pacific, in charge of Alexander Agassiz, by the U.S. Fish Commission steamer "Albatross," from August, 1899, to March, 1900, Commander Jefferson F. Moser, U. S. N., commanding. III. Medusae. Memoirs of the Museum of Comparative Zoölogy at Harvard College, 26, 139-176 (pl. 6).

Bentlage, B., Cartwright, P., Yanagihara, A.A., Lewis, C., Richards, G.S. \& Collins, A.G. (2010) Evolution of box jellyfish (Cnidaria: Cubozoa), a group of highly toxic invertebrates. Proceedings of the Royal Society B, 277, 493501.

Bigelow, H.B. (1938) Plankton of the Bermuda oceanographic expeditions. VII. Medusae taken during the years 1929 and 1930. Zoologica. Scientific contributions of the New York Zoological Society, 23, 99-189.

Gershwin, L. (2005) Carybdea alata auct. and Manokia stiasnyi, reclassification to a new family with description of a new genus and two new species. Memoirs of the Queensland Museum, 51, 501-523.

Mariscal, R.N. (1974) Nematocysts. In: Muscatine, L., \& Lenhoff, H.M. (Eds.), Coelenterate biology - reviews and new perspectives. Academic Press, New York, pp. 129-178.

Mayer, A.G. (1910) Medusae of the World. Volume III. The Scyphomedusae. Carnegie Institution of Washington Publication, 109(3), 499-735 pp.

Östman, C. (2000) A guideline to nematocyst nomenclature and classification, and some notes on the systematic value of nematocysts. In: Mills, C.E., Boero, F., Migotto A., \& Gili J.M. (Eds.), Trends in hydrozoan biology - IV. Scientia Marina, 64 (Supl. 1), 31-46. 